\title{
Effect of Metal on the Ethylene Polymerization Behavior of a Diimine-Based Homogeneous Late Transition Metal Catalyst System
}

\author{
Timo V. Laine, ${ }^{a, *}$ Martti Klinga, ${ }^{a}$ Arto Maaninen, ${ }^{b}$ Erkki Aitola ${ }^{a}$ and Markku Leskelä ${ }^{a}$ \\ ${ }^{a}$ Laboratory of Inorganic Chemistry, Department of Chemistry, PO Box 55, FIN-00014 University of Helsinki, Finland \\ and ${ }^{b}$ Department of Chemistry, University of Oulu, PO Box 333, FIN-90571 Oulu, Finland
}

\begin{abstract}
Laine, T. V., Klinga, M., Maaninen, A., Aitola, E. and Leskelä, M., 1999. Effect of Metal on the Ethylene Polymerization Behavior of a Diimine-Based Homogeneous Late Transition Metal Catalyst System. Acta Chem. Scand. 53: 968-973. (C) Acta Chemica Scandinavica 1999.

The cobalt(II) complex (1) of the didentate nitrogen ligand $N, N^{\prime}-1,2-$ ethanediylidenebis[2,6-bis(1-methylethyl)phenylamine] (L) was synthesized and tested in ethylene polymerization. The solid state structures of $\mathbf{1}$ and $\mathbf{L}$ were determined by single-crystal X-ray diffraction. After activation with methylaluminoxane complex 1 produced mainly branched oligomers with clearly lower activity than observed for the corresponding nickel compound (2).
\end{abstract}

Alkene polymerization processes catalyzed by transition metals have become of great importance to the polyolefin industry, and therefore the evolution of these systems has been rapid, especially during the past 15 years. ${ }^{1}$ The development of single-site catalysts, such as Group 4 metallocenes, ${ }^{2-5}$ with well defined active centers and catalyst structures has provided a tool to tailor polymer properties through fine-tuning of the catalyst precursor. ${ }^{6}$

Traditionally late transition metal compounds were considered to be able to produce only short-chain alkene oligomers with not more than 40 carbon atoms owing to the highly competitive chain termination step. ${ }^{7-9}$ This feature, however, is utilized in the Shell Higher Olefin Process (SHOP) where nickel-catalyzed oligomerization of ethylene is followed by conversion via isomerization, metathesis and hydroformylation to primary $\mathrm{C}_{11}-\mathrm{C}_{15}$ alcohols, which serve as feedstock for the detergent industry. ${ }^{10}$ Production of long-chain polyethylene had not been accomplished with late transition metal based catalysts until in 1995, when the group of Brookhart reported the discovery of nickel and palladium complexes bearing sterically demanding $\alpha$-diimine-type diazabutadiene ligands. ${ }^{11}$ Depending on the ligand substitution pattern and process parameters these catalysts can produce ethylene homopolymers varying from linear high-density material to highly branched, amorphous polyethylene, which has similar properties as low-density polyethylene (LDPE). Such catalyst systems may prove to provide a cost-effective alternative to the currently used, energyintensive radical process which requires high temperature

\footnotetext{
* To whom correspondence should be addressed.
}

(above $160^{\circ} \mathrm{C}$ ) and pressure (ca. 2000 bar) ${ }^{12}$ for LDPE production. With simple precursor modifications the product distribution can be shifted to the direction of linear oligomers ${ }^{13}$ or the incorporation of polar comonomers, such as alkyl acrylates, into the polymer chain ${ }^{14}$ can be achieved. Resulting industrial interest ${ }^{15}$ has led to an extensive patent application covering the syntheses of numerous diazabutadiene-based transition metal compounds and their use as polymerization catalysts. ${ }^{16}$

In this article we present the synthesis and characterization of dibromo- $N, N^{\prime}$-1,2-ethanediylidenebis[2,6-bis(1methylethyl)phenylamine]cobalt(II) (1), the cobalt analog of the reported catalyst precursors, ${ }^{11}$ and compare its ethylene polymerization behavior with the corresponding nickel complex (2).

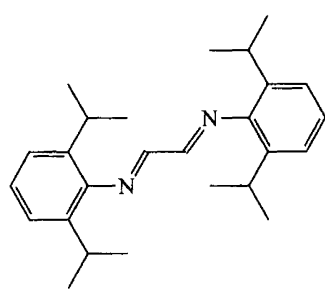

$\mathbf{L}$

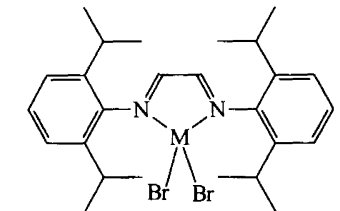

1: $\mathrm{M}=\mathrm{Co}$ 2: $\mathrm{M}=\mathrm{Ni}$
Scheme 1.

\section{Results and discussion}

Synthesis of catalyst precursors. The ligand $\mathbf{L}$ can be readily synthesized by acid-catalyzed coupling of 1,2- 
Table 1. Ethylene polymerization with complexes 1 and $2 / \mathrm{MAO}^{a}$

\begin{tabular}{llllllllll}
\hline Entry & Catalyst & $T_{\mathrm{p}} /{ }^{\mathrm{C}} \mathrm{C}^{b}$ & $n_{\text {cat }} / \mu \mathrm{mol}^{c}$ & $p /$ bar $^{d}$ & Yield $/ \mathrm{g}$ & Activity & $M_{\mathrm{w}} / 10^{3} \mathrm{~g} \mathrm{~mol}^{-1}$ & $M_{\mathrm{w}} / M_{\mathrm{n}}$ & $T_{\mathrm{m}} /{ }^{\circ} \mathrm{C}$ \\
\hline 1 & 1 & 0 & 10 & 3.0 & 0.46 & $1040^{f}$ & $1.2^{g}$ & N.d. & Oil \\
2 & 1 & 20 & 10 & 4.3 & 0.45 & $540^{f}$ & $0.5^{g}$ & N.d. & Oil \\
3 & 1 & 40 & 10 & 5.5 & 0.17 & $250^{f}$ & $0.6^{g}$ & N.d. & Oil \\
4 & 2 & 0 & 2.5 & 3.0 & 1.4 & 2290 & 530 & 2.0 & 133 \\
5 & 2 & 20 & 2.5 & 4.3 & 3.5 & 5570 & 350 & 1.9 & 132 \\
6 & 2 & 40 & 2.5 & 5.5 & 5.8 & 9330 & 260 & 2.5 & 123 \\
\hline
\end{tabular}

${ }^{a}[\mathrm{Al}]:[\mathrm{M}]=2000, \mathrm{M}=\mathrm{Co}, \mathrm{Ni} .{ }^{b}$ Polymerization temperature. ${ }^{c}$ Molar amount of the catalyst precursor. ${ }^{d}$ Ethylene pressure. ${ }^{e}$ Activity in $\mathrm{kg} \mathrm{PE}$ [mol (catalyst) $\left.\mathrm{h}\right]{ }^{-1}$. ${ }^{f}$ Calculated from observed ethylene consumption due to the loss of volatile products during isolation. ${ }^{g}$ Based on ${ }^{1} \mathrm{H}$ NMR analysis of the isolated fraction. ${ }^{h}$ Peak melting temperature.

ethanedial with 2,6-di(1-methylethyl)phenylamine. Owing to the relatively good solubility of anhydrous cobalt(II)bromide into organic solvents, the direct reaction of the metal halide and the ligand in dry THF could be performed, producing the cobalt complex 1 in good yield $(83 \%)$. Preceding synthesis of the solvent adductbased metal precursor as in the case of the nickel analog 2 was not, therefore, necessary. The disappearance of the ligand nitrogen signal at $-13 \mathrm{ppm}$ in the ${ }^{14} \mathrm{~N}$ NMR spectrum $\dagger$ together with the observed changes in chemical shifts in the ${ }^{13} \mathrm{C}$ spectrum indicates complex formation, which was also confirmed by crystallographic analysis.

Polymerization behavior. The polymerization conditions and results with catalysts $1 / \mathrm{MAO}$ and 2/MAO are summarized in Table 1 . The behavior of $2 / \mathrm{MAO}$, which was used as a reference system, followed the trends reported in the literature ${ }^{11,17}$ with high catalytic activity, narrow molecular weight distribution, and high molecular weight for the produced polymer. The cobalt complex 1 could also be activated with MAO for the polymerization of ethylene, but three notable differences were observed in comparison with the nickel analog.

Changing the metal center from nickel to cobalt leads to a drastic decline in catalytic activity (Fig. 1). At $0{ }^{\circ} \mathrm{C}$ the decrease is $55 \%$, from $2290 \mathrm{~kg}$ (polymer) (mol catalyst) ${ }^{-1} \mathrm{~h}^{-1}$ (Table 1 , entry 4) to $1040 \mathrm{~kg}$ (polymer) (mol catalyst) ${ }^{-1} \mathrm{~h}^{-1}$ (entry 1 ), but at $40^{\circ} \mathrm{C}$ the drop is even more dramatic (97\%) from $9330 \mathrm{~kg}$ (polymer) (mol catalyst) ${ }^{-1} \mathrm{~h}^{-1}$ to $250 \mathrm{~kg}$ (polymer) (mol catalyst) $)^{-1} \mathrm{~h}^{-1}$ (entries 6 and 3, respectively). An interesting feature is the contrast between the two systems in trends of activity development at different temperatures. The nickel catalyst loses activity with decreasing polymerization temperature, as observed also previously, ${ }^{11,18}$ while the cobalt system proves to be more active at lower temperatures. In fact, the polymerization activity of $1 / \mathrm{MAO}$ quadruples as the temperature is dropped from 40 to $0^{\circ} \mathrm{C}$. As shown in Fig. 2, which displays the ethylene consumption as a function of time for both catalysts $1 / \mathrm{MAO}$ and 2/MAO, for the nickel catalyst $2 / \mathrm{MAO}$ a relatively steady con-

$\dagger$ The chemical shift for the cobalt complex could not be seen in ${ }^{14} \mathrm{~N}$ NMR, which apparently results from the broadening effect caused by the associated metal.

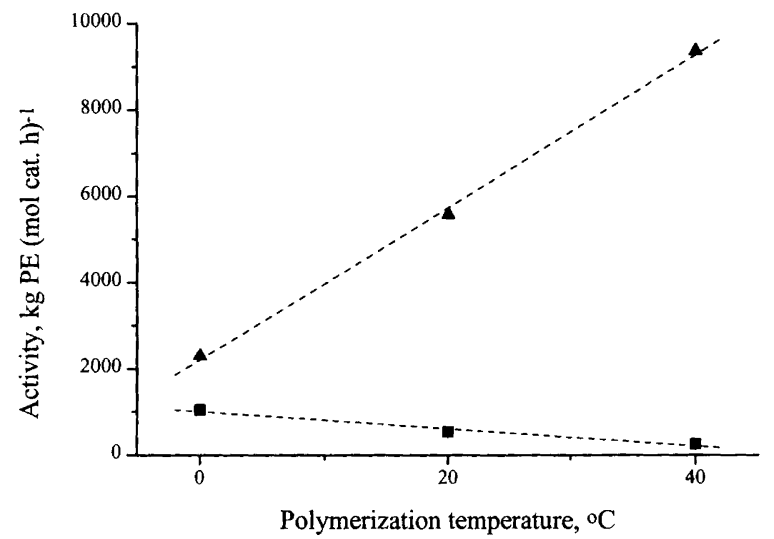

Fig. 1. Catalytic activity of $1 / \mathrm{MAO}(\boldsymbol{\square})$ and $2 / \mathrm{MAO}(\Delta)$ at different polymerization temperatures.

sumption rate is reached after the initial peak except at $40^{\circ} \mathrm{C}$, when following a 4-min period of high activity the consumption drops significantly. Similarly, the highest activity for the counter-ion-activated nickel complex has been reported at $20^{\circ} \mathrm{C}$, after which a sudden decline was observed. ${ }^{18}$ With the cobalt-based system 1/MAO at $40^{\circ} \mathrm{C}$ the activity is lost completely after $5 \mathrm{~min}$, and even at $0{ }^{\circ} \mathrm{C}$ the consumption of ethylene declines constantly. This behavior may be attributed to the thermal instability of the alkyl-containing species, which at least in the case of nickel(II) are relatively temperature sensitive. ${ }^{19}$

Also product patterns for the two catalysts are remarkably dissimilar. While solid, long-chain polyethylene $\left(M_{\mathrm{w}}\right.$ up to $\left.530000 \mathrm{~g} \mathrm{~mol}^{-1}\right)$ is produced with the nickel catalyst, 1/MAO yields mainly branched oligomeric oils. Polymerization attempts even at $-15^{\circ} \mathrm{C}$ did not provide any solid material. This is an indication that the benefit of bulky ligands, which enhance chain growth by retarding the chain termination processes, ${ }^{20}$ is counterbalanced by the unfavorable electronic effect of the cobalt center, thus steering the product distribution towards lower molecular weights. However, addition of even further steric protection and an auxiliary nitrogen donor, as in triimine-type 2,6-bis(arylimino) pyridyl complexes of cobalt(II) and iron(II), which display distorted square-pyramidal-type coordination, seems to compensate for this effect and enables the production of polymers with higher molecular weights. ${ }^{21,22}$ 

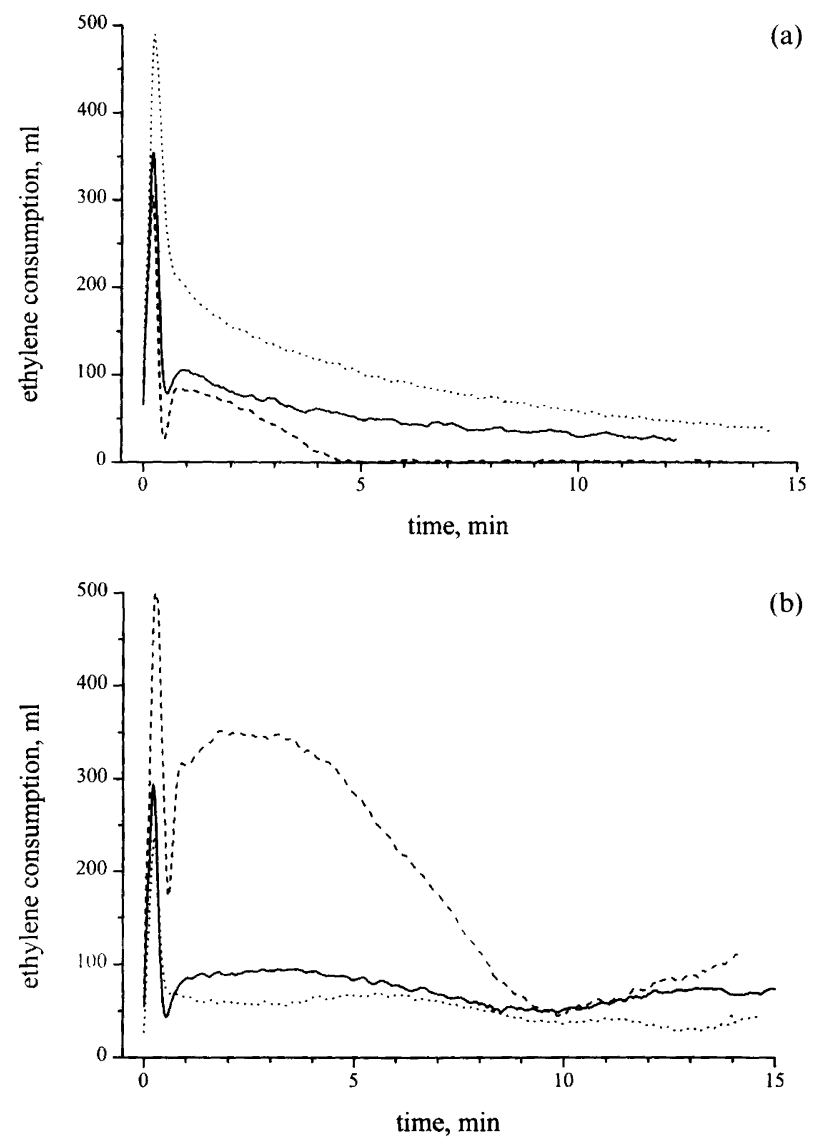

Fig. 2. Observed ethylene consumption during polymerization at $40(----), 20(-)$, and $0(\cdots \cdots \cdots) \cdot)^{\circ} \mathrm{C}$ with the catalyst: (a) $1 / \mathrm{MAO}$, (b) $2 / \mathrm{MAO}$.

Single-crystal XRD studies. Crystal data, together with the data collection and structure refinement parameters, are presented in Table 2. Selected bond lengths and angles are given in Table 3 . The cobalt complex 1 crystallizes in the monomeric form, in which the cobalt atom lies on a two-fold rotation axis and the asymmetric unit is therefore formed only by a half of the molecule. Owing to this symmetry both cobalt-bromine bonds ( $\mathrm{Co}-\mathrm{Br}$

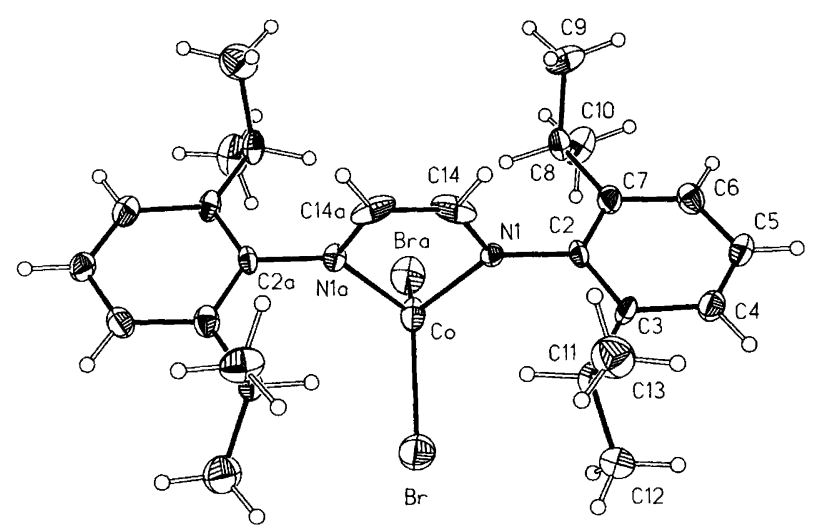

Fig. 3. Molecular structure of complex 1 showing the labeling scheme. Displacement ellipsoids are drawn at the $40 \%$ probability level. and $\mathrm{Co}-\mathrm{Bra})$ are identical $(2.34 \AA)$, as are also the cobalt-nitrogen bonds (Co-N1 and Co-N1a, $2.05 \AA$ ).

The cobalt center, $\mathrm{Co}$, is coordinated to two bromine atoms ( $\mathrm{Br}$ and $\mathrm{Bra})$ and two nitrogen atoms ( $\mathrm{N} 1$ and N1a) of the didentate ligand, forming a tetrahedral coordination sphere around the metal (Fig. 3). The small $\mathrm{N} 1-\mathrm{Co}-\mathrm{N} 1 \mathrm{a}$ angle $80.8(4)^{\circ}$ distorts the tetrahedron as observed in other diimine cobalt compounds. ${ }^{23,24}$ The five-membered metallacycle (Co-N1-C14-C14a-N1a) is nearly planar, the maximal deviation from the plane being only $0.003 \AA$ for atoms $\mathrm{C} 14$ and $\mathrm{C} 14 \mathrm{a}$. The two phenyl rings adopt a position almost perpendicular to the metallacycle plane, with the phenyl-metallacycle angle $88.9(2)^{\circ}$, and thus shield the metal center.

Complex formation affects bond lengths in the diazabutadiene bridge $(\mathrm{N} 1-\mathrm{Cl} 14-\mathrm{Cl}$ a $-\mathrm{N} 1 \mathrm{a})$ by decreasing the $\mathrm{C}-\mathrm{C}$ bond $(\mathrm{C} 14-\mathrm{C} 14 \mathrm{a})$ from $1.467(5) \AA$ for the ligand to 1.33(2) $\AA$ for the complex and lengthening the $\mathrm{C}=\mathrm{N}$ double bonds $(\mathrm{N} 1-\mathrm{C} 14$ and $\mathrm{N} 1 \mathrm{a}-\mathrm{C} 14 \mathrm{a})$ from $1.266(3)$ to $1.340(12) \AA$. This indicates partial delocalization of the double bonds in the bridge owing to backbonding from the metal to the ligand (for a similar iron complex, see Ref. 25). The introduction of alkynes and other electrophilic components to the metal coordination sphere overrides this effect. ${ }^{26}$ Also, when the phenyl groups are replaced by alkyl groups, such as tert-butyl, the $\mathrm{C}=\mathrm{N}$ bonds retain their double bond character even after complexation. ${ }^{23}$

Crystallographic data (excluding structure factors) for the structures reported in this paper have been deposited with the Cambridge Crystallographic Data Centre as supplementary publications nos. CCDC-101588 (compound L) and CCDC-101589 (compound 1) $\dagger$

\section{Conclusions}

The cobalt $\alpha$-diimine complex dibromo- $N, N^{\prime}-1,2-$ ethanediylidenebis[2,6 - bis( 1 - methylethyl)phenylamine]cobalt(II) (1) can be activated for ethylene polymerization with MAO in a similar fashion as the analogous nickel precursors. ${ }^{11,17}$ Industrial applicability of the cobalt compound suffers, however, from three apparent weaknesses: (i) Polymerization activity of the cobalt system was only moderate and clearly lower than observed for the corresponding nickel-based system. (ii) At polymerization temperatures above $0{ }^{\circ} \mathrm{C}$ a rapid loss of activity occurred with the cobalt species after the initial peak of ethylene consumption. (iii) 1/MAO yielded exclusively short-chain products, while solid, high molecular weight material was produced with the nickel system.

\section{Experimental}

Materials. All complex preparations were carried out under an argon atmosphere using standard Schlenk

$\dagger$ Copies of the data can be obtained on application to CCDC, 12 Union Road, Cambridge CB2 1EZ, UK; Fax: +44-1223336 033; e-mail: deposit@ccdc.cam.ac.uk. 
Table 2. Crystallographic data for $L$ and 1.

\begin{tabular}{|c|c|c|}
\hline & $\mathbf{L}$ & 1 \\
\hline $\begin{array}{l}\text { Empirical formula } \\
\text { Formula weight }\end{array}$ & $\begin{array}{l}\mathrm{C}_{26} \mathrm{H}_{36} \mathrm{~N}_{2} \\
376.57\end{array}$ & $\begin{array}{l}\mathrm{C}_{26} \mathrm{H}_{36} \mathrm{Br}_{2} \mathrm{CoN}_{2} \\
595.32\end{array}$ \\
\hline Crystal color and form & Yellow, plate & Brown, prismatic \\
\hline Crystal system & Monoclinic & Monoclinic \\
\hline Space group & $P 2_{1} / c$ & $C 2 / c$ \\
\hline$a / \AA ̊$ & $8.624(2)$ & $20.864(6)$ \\
\hline$b / A ̊$ & $12.710(3)$ & $6.882(4)$ \\
\hline$c / \AA$ & $10.868(2)$ & $19.890(6)$ \\
\hline$\beta /{ }^{\circ}$ & $92.89(3)$ & $106.77(4)$ \\
\hline$V / \AA^{3}$ & $1189.7(5)$ & $2735(2)$ \\
\hline$z$ & 2 & 4 \\
\hline$D_{\mathrm{c}} / \mathrm{Mg} \mathrm{m}^{-3}$ & 1.051 & 1.446 \\
\hline Absorption coefficient $\mu / \mathrm{mm}^{-1}$ & 0.061 & 3.565 \\
\hline$F(000)$ & 412 & 1212 \\
\hline Crystal size $/ \mathrm{mm}$ & $0.30 \times 0.25 \times 0.25$ & $0.25 \times 0.10 \times 0.08$ \\
\hline Scan mode & $\omega-2 \theta$ & $\omega-2 \theta$ \\
\hline$\theta_{\max } /^{\circ}$ & 24.98 & 25.01 \\
\hline No. of unique reflections & 1713 & 2038 \\
\hline No. of observed reflections $[/>2 \sigma(I)]$ & 1222 & 1414 \\
\hline No. of reflections used in refinement & 1698 & 2013 \\
\hline No. of parameters & 127 & 145 \\
\hline Goodness-of-fit on $F^{2 a}$ & 1.045 & 1.009 \\
\hline Final $R$-indices $[/>2 \sigma(/)]^{b}$ & $R=0.0613, w R=0.1413$ & $R=0.0793, w R=0.1892$ \\
\hline$R$-indices (all data) ${ }^{b}$ & $R=0.0935, w R=0.1588$ & $R=0.1190, w R=0.2183$ \\
\hline Largest differential peak and hole $/ \mathrm{e}^{-3}$ & 0.155 and -0.222 & $1.911^{c}$ and -0.657 \\
\hline
\end{tabular}

${ }^{a} S=\left[\Sigma\left[w\left(F_{0}^{2}-F_{\mathrm{c}}{ }^{2}\right)^{2}\right] /(n-p)\right]^{1 / 2}$, where $n=$ data and $p=$ parameters. ${ }^{b} R=\Sigma|| F_{\mathrm{o}}|-| F_{\mathrm{c}}|| / \Sigma\left|F_{\mathrm{o}}\right|$ with $F>4 \Sigma(F)$; function minimized is $w R=\left[\Sigma\left[w\left(F_{\mathrm{o}}{ }^{2}-F_{\mathrm{c}}{ }^{2}\right)^{2}\right] / \Sigma\left[w\left(F_{\mathrm{o}}{ }^{2}\right)^{2}\right]\right]^{1 / 2}$. ${ }^{c}$ Maximum residual electron density $1.911 \mathrm{e} \AA^{-3}$; peak coordinates $x=0.4701, y=$ $0.5027, z=0.1466$; distance to nearest atom $(\mathrm{Br}) 1.22 \AA$.

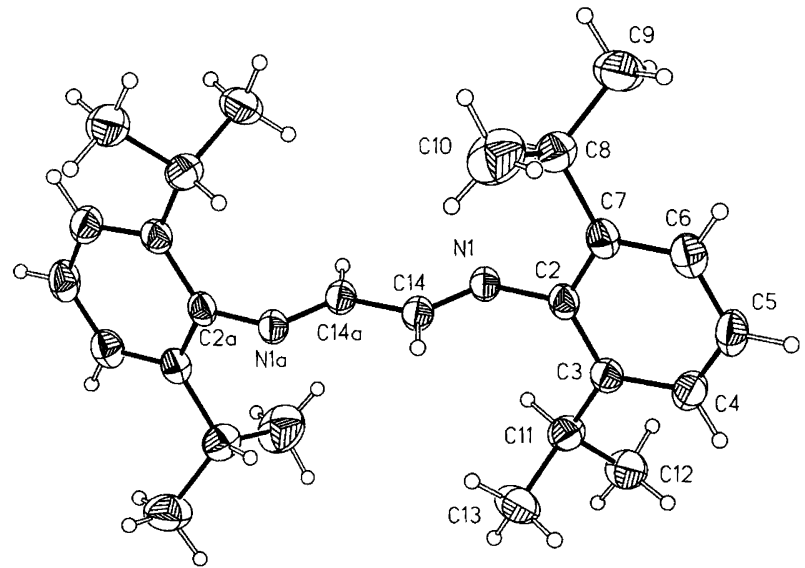

Fig. 4. X-Ray crystal structure of the ligand $L$ with the labeling scheme. Displacement ellipsoids are drawn at the $40 \%$ probability level.

techniques. Solvents were dried by refluxing with a drying agent $\left(\mathrm{P}_{2} \mathrm{O}_{5}\right.$ for dichloromethane and sodium/ benzophenone for the non-halogenated solvents) and distillation under argon. Dibromo(1,2-dimethoxyethane)nickel(II) [(DME) $\left.\mathrm{NiBr}_{2}\right]$ was prepared according to the literature. ${ }^{27}$ Anhydrous $\mathrm{CoBr}_{2}$ (Aldrich, 99\%), 1,2-ethanedial (Fluka, 40\% solution in water) and 2,6di(1-methylethyl)phenylamine (Aldrich, 90\%) were used as received.
Product analysis. Synthesis products were characterized with a Varian Gemini $200\left({ }^{1} \mathrm{H}\right.$ NMR $)$ or a Bruker DPX$400\left({ }^{13} \mathrm{C}\right.$ and ${ }^{14} \mathrm{~N}$ NMR $)$ spectrometer. ${ }^{1} \mathrm{H}$ and ${ }^{14} \mathrm{~N}$ spectra were recorded in $\mathrm{CDCl}_{3}$ (TMS as internal standard at $0 \mathrm{ppm})$ and tetrahydrofuran $\left(\mathrm{N}_{2}\right.$ as internal standard at $-72 \mathrm{ppm})$, respectively. ${ }^{13} \mathrm{C}$ NMR measurements were performed in tetrahydrofuran without internal standards scaling the spectra with the two solvent peaks. Elemental analyses were carried out at the University of Ulm, Germany. For polymer molecular weights and molecular weight distributions a Waters 150-C GPC chromatograph was used operating at $135^{\circ} \mathrm{C}$ with $1,2,4$ trichlorobenzene solvent and polystyrene calibration standards. Melting points were determined by differential scanning calorimetry using a Perkin Elmer DSC-2 calorimeter.

$\mathrm{N}, \mathrm{N}^{\prime}$-1,2-ethanediylidenebis [2,6-bis(1-methylethyl) phenylamine] (L). The ligand was synthesized by literature methods. ${ }^{28}$ Crystallization from ethanol yielded bright yellow plates ready for X-ray analysis. Found: $\mathrm{C} 82.88$; $\mathrm{H} 9.60 ; \mathrm{N}$ 7.17. Calc. for $\mathrm{C}_{26} \mathrm{H}_{36} \mathrm{~N}_{2}$ : C 82.92; $\mathrm{H} \mathrm{9.64;} \mathrm{N}$ 7.44. ${ }^{1} \mathrm{H}$ NMR $\left(\mathrm{CDCl}_{3}\right): \delta 1.21\left(\mathrm{~d}, 12 \mathrm{H}, \mathrm{H}_{\mathrm{Me}}\right), 2.92(\mathrm{~m}$, $2 \mathrm{H}, \mathrm{CH} \mathrm{Me}_{2}$ ), 7.03-7.25 (m, $\left.3 \mathrm{H}, H_{\text {arom }}\right), 8.10$ (s, $1 \mathrm{H}$, $\left.\mathrm{C}_{\text {bridge }}\right)$ ppm. ${ }^{13} \mathrm{C}$ NMR (THF): $\delta 22.5\left(C_{\mathrm{Me}}\right), 27.8$ $\left(C \mathrm{HMe}_{2}\right), 122.7\left(C_{\text {arom,m }}\right), 124.6\left(C_{\text {arom,p }}\right), 136.1\left(C_{\text {arom,o }}\right)$, $148.4\left(\mathrm{NC}_{\text {arom }}\right), 163.2(C=\mathrm{N}) \mathrm{ppm} .{ }^{14} \mathrm{~N}$ NMR (THF): $\delta-13 \mathrm{ppm}$. 
Table 3. Selected bond lengths (in $\AA$ ) and angles (in ${ }^{\circ}$ ) for $L$ and 1.

\section{L}

Bond lengths

$\begin{array}{ll}\mathrm{N} 1-\mathrm{C} 2 & 1.433(3) \\ \mathrm{N} 1-\mathrm{C} 14 & 1.266(3) \\ \mathrm{C} 14-\mathrm{C} 14 \mathrm{a}^{\mathrm{i}} & 1.467(5)\end{array}$

Bond angles

N1-C2-C3

$\mathrm{N} 1-\mathrm{C} 2-\mathrm{C} 7$

N1-C14-C14ai

C2-N1-C14

118.6(2)

$119.1(2)$

$120.2(3)$

119.5(2)

1

Bond lengths

$\mathrm{Co}-\mathrm{Br}$

Co-N1

$\mathrm{N} 1-\mathrm{C} 2$

N1-C14

C14-C14ai

Bond angles

$\mathrm{Br}-\mathrm{Co}-\mathrm{Bra}^{\mathrm{ii}}$

$\mathrm{N} 1-\mathrm{Co}-\mathrm{Br}$

N1-Co-Brai

N1-Co-N1aii

$\mathrm{N} 1-\mathrm{C} 2-\mathrm{C} 3$

$\mathrm{N} 1-\mathrm{C} 2-\mathrm{C} 7$

N1-C14-C14aii

C2-N1-C14

$2.343(2)$

$2.049(6)$

$1.453(10)$

$1.340(12)$

$1.33(2)$

Symmetry transformations used to generate equivalent atoms: ${ }^{i}-x+1,-y+1,-z{ }^{i i}-x+1, y,-z+1 / 2$.

Dibromo-N, $\mathrm{N}^{\prime}$-1,2-ethanediylidenebis [2,6-bis (1-methylethyl)phenylamine ] cobalt(II) (1). To a solution of anhydrous $\mathrm{CoBr}_{2}(1.40 \mathrm{~g}, 6.40 \mathrm{mmol})$ in $15 \mathrm{ml}$ THF was added the yellow ligand solution $(2.49 \mathrm{~g}, 6.63 \mathrm{mmol}$ in $15 \mathrm{ml}$ THF). The resulting green-brown solution was stirred for $24 \mathrm{~h}$ at room temperature. After solvent evaporation the greenish brown (moss green) powder was washed with hexane $(4 \times 20 \mathrm{ml})$, filtered, and dried in vacuo. Yield $3.15 \mathrm{~g}(83 \%)$. Brown crystals for X-ray measurement were obtained by slow evaporation of the solvent mixture THF-pentane $(2: 1)$. Found: C $52.39 ; \mathrm{H}$ $6.15 ; \mathrm{N}$ 4.74. Calc. for $\mathrm{C}_{26} \mathrm{H}_{36} \mathrm{Br}_{2} \mathrm{CoN}_{2}$ : C 52.46; $\mathrm{H}$ $6.10 ; \mathrm{N}$ 4.71. ${ }^{13} \mathrm{C}$ NMR (THF): $\delta 18.6\left(C_{\mathrm{Me}}\right), 26.1$ $\left(\mathrm{CHMe}_{2}\right), 116.4\left(C_{\text {arom,m }}\right), 120.8\left(C_{\text {arom,p }}\right), 132.2\left(C_{\text {arom }, \mathrm{o}}\right)$, $144.8\left(\mathrm{~N} C_{\text {arom }}\right), 158.6(C=\mathrm{N}) \mathrm{ppm}$.

Dibromo-N, $\mathrm{N}^{\prime}$ - 1,2-ethanediylidenebis [2,6-bis (1-methylethyl) phenylamine]nickel(II) (2). The nickel complex was prepared from [(DME) $\left.\mathrm{NiBr}_{2}\right]$ and $\mathbf{L}$ as described in the literature. ${ }^{11}$ Found: C 52.23; H 6.06; N 5.19. Calc. for $\mathrm{C}_{26} \mathrm{H}_{36} \mathrm{Br}_{2} \mathrm{~N}_{2} \mathrm{Ni}$ : C 52.48; $\mathrm{H} 6.10 ; \mathrm{N} 4.71$.

$X$-Ray crystallography. The crystals were mounted on a glass fiber using the oil-drop method. ${ }^{29}$ Crystal data obtained with the $\omega-2 \theta$ scan mode were collected on an automated four-circle Rigaku AFC-7S diffractometer using graphite monochromatized Mo $\mathrm{K} \alpha$ radiation $(\lambda=0.71073 \AA)$ at $193 \mathrm{~K}$. Three standard reflections were monitored after every 200 intensity scans. The intensities were corrected for Lorentz and polarization effects. For compound $1 \psi$-scans were used for absorption correction. Data sets were compressed to reflection files with TEXSAN Single Crystal Structure Analysis Software. ${ }^{30}$ The structures were solved with the SHELXTL PC 4.1 program package ${ }^{31}$ using direct methods, while further refinement with full-matrix least-squares on $|F|^{2}$ was carried out with SHELXL 93. ${ }^{32}$ All non-hydrogen atoms were refined anisotopically. Hydrogen atoms were introduced to calculated positions (riding model) with 1.2 times the displacement factors of the host carbon atoms.

Ethylene polymerization experiments. Methylaluminoxane ( $30 \mathrm{wt} \%$ solution in toluene) was acquired from Witco. Toluene (Lab Scan, analytical grade) was refluxed with metallic sodium and distilled under argon. Polymerization-grade ethylene was purchased from AGA and used without further purification.

Polymerization runs were performed at a constant monomer concentration $\left(0.55 \mathrm{~mol} \mathrm{dm}^{-3}\right)^{33}$ in a Büchi $1.0 \mathrm{dm}^{3}$ glass or stainless steel autoclave equipped with a Julabo ATS-3 or Lauda RK 20 temperature controlling unit, respectively. Mechanical stirring was applied at the stirring speed of 800 r.p.m. During polymerization the partial pressure of ethylene was maintained constant by an electronic controlling system. Ethylene consumption was measured with a calibrated mass flow meter and monitored on line together with the temperature and pressure inside the vessel using the Genie ${ }^{\circledR}$ computer program for data acquisition. ${ }^{34}$

Toluene $\left(300 \mathrm{~cm}^{3}\right)$ and the cocatalyst were introduced to the argon-purged reactor. Once the polymerization temperature had been reached the vessel was charged with ethylene to the appropriate pressure. Polymerization was commenced by pumping $20 \mathrm{~cm}^{3}$ of the catalyst

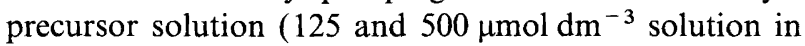
toluene for $\mathrm{Ni}$ and $\mathrm{Co}$, respectively) into the reactor. After 15 min polymerization was quenched by pouring the contents of the vessel into methanol acidified with a small amount of aqueous hydrochloric acid. The solid polymer was collected by filtration, washed with methanol and dried under vacuum. If no precipitation was observed the whole mixture was washed with water, the separated organic phase was dried with $\mathrm{MgSO}_{4}$ and solvents were evaporated yielding a colorless oil, which was dried in vacuo.

Acknowledgements. Financial and material support from the Academy of Finland, the Technology Development Centre of Finland (TEKES), and Borealis Polymers Oy is gratefully acknowledged. Elemental analyses were made possible by Dr. Ulf Dietrich (University of Ulm, Germany). 


\section{References}

1. Montagna, A. A., Burkhart, R. M. and Dekmezian, A. H. Chemtech 27 (12) (1997) 26.

2. Brintzinger, H. H., Fischer, D., Mülhaupt, R., Rieger, B. and Waymouth, R. M. Angew. Chem., Int. Ed. Engl. 34 (1995) 1143.

3. Kaminsky, W. Macromol. Chem. Phys. 197 (1996) 3907.

4. Bochmann, M. J. Chem. Soc., Dalton Trans. (1996) 255.

5. Kaminsky, W. and Arndt, M. Adv. Polym. Sci. 127 (1997) 143

6. Thayer, A. M. Chem. Eng. News 73 (37) (1995) 15.

7. Keim, W., Behr, A. and Röper, M. In Wilkinson, G., Stone, F. G. A. and Abel, E. W., Eds. Comprehensive Organometallic Chemistry, Pergamon Press, Oxford 1982, Vol. 8, p. 371

8. Jolly, P. W. In Wilkinson, G., Stone, F. G. A. and Abel, E. W., Eds. Comprehensive Organometallic Chemistry, Pergamon Press, Oxford 1982, Vol. 8, p. 613.

9. al-Jarallah, A. M., Anabtawi, J. A., Siddiqui, M. A. B., Aitani, A. M. and al-Sa'doun, A. W. Catal. Today 14 (1992) 42.

10. Lappin, G. R., Nemec, L. H., Sauer, J. D. and Wagner, J. D. In Kroschwitz, J. I. and Howe-Grant, M., Eds. KirkOthmer Encyclopedia of Chemical Technology, 4th Edn., John Wiley \& Sons, New York 1996, Vol. 17, p. 839.

11. Johnson, L. K., Killian, C. M. and Brookhart, M. J. Am. Chem. Soc. 117 (1995) 6414.

12. Whiteley, K. S., Heggs, T. G., Koch, H., Mawer, R. L. and Immel, W. In Elvers, B., Hawkins, S. and Schulz, G., Eds. Ullman's Encyclopedia of Industrial Chemistry, 5th Edn., VCH Publishers, Weinheim 1992, Vol. A21, p. 487.

13. Killian, C. M., Johnson, L. K. and Brookhart, M. Organometallics 16 (1997) 2005.

14. Johnson, L. K., Mecking, S. and Brookhart, M. J. Am. Chem. Soc. 118 (1996) 267.

15. Haggin, J. Chem. Eng. News 74 (6) (1996) 6.

16. Johnson, L. K., Killian, C. M., Arthur, S. D., Feldman, J., McCord, E. F., McLain, S. J., Kreutzer, K. A., Bennett, M. A., Coughlin, E. B., Ittel, S. D., Parthasarathy, A., Tempel, D. J. and Brookhart, M. S. PCT Int. Appl. 96/23010 (1996).

17. Pappalardo, D., Mazzeo, M. and Pellecchia, C. Macromol. Rapid Commun. 18 (1997) 1017.
18. de Souza, R. F., Mauler, R. S., Simon, L. C., Nunes, F. F., Vescia, D. V. S. and Cavagnolli, A. Macromol. Rapid Commun. 18 (1997) 795.

19. Svoboda, M. and tom Dieck, H. J. Organomet. Chem. 191 (1980) 321.

20. Deng, L., Woo, T. K., Cavallo, L., Margl, P. M. and Ziegler, T. J. Am. Chem. Soc. 119 (1997) 6177.

21. Britovsek, G. J. P., Gibson, V. C., Kimberley, B. S., Maddox, P. J., McTavish, S. J., Solan, G. S., White, A. J. P. and Williams, D. J. J. Chem. Soc., Chem. Commun. (1998) 849.

22. Small, B. L., Brookhart, M. and Bennett, A. M. A. J. Am. Chem. Soc. 120 (1998) 4049.

23. Barral, M. C., Delgado, E., Gutiérrez-Puebla, E., JimenezAparicio, R., Monge, A., Del Pino, C. and Santos, A. Inorg. Chim. Acta 74 (1983) 101.

24. Baker, G. L., Fronczek, F. R., Kiefer, G. E., Marston, C. R., Modenbach, C. L., Newkome, G. R., Puckett, W. E. and Watkins, S. F. Acta Crystallogr., Sect. C 44 (1988) 1668.

25. Diercks, R., Kopf, J. and tom Dieck, H. Acta Crystallogr., Sect. C 40 (1984) 363.

26. Kokkes, M. W., Stufkens, D. J. and Oskam, A. J. Chem. Soc., Dalton Trans. (1983) 439.

27. Ward, L. G. L. Inorg. Synth. 12 (1972) 154.

28. tom Dieck, H., Svoboda, M. and Greiser, T. $Z$. Naturforsch., Teil B 36 (1981) 823.

29. Kottke, T. and Stalke, D. J. Appl. Crystallogr. 26 (1993) 615.

30. TEXSAN: Single Crystal Structure Analysis Software, Version 1.6, Molecular Structure Corporation, The Woodlands, TX 1993.

31. Sheldrick, G. M. SHELXTL PC Realease 4.1, Siemens Analytical X-Ray Instruments Inc., Madison, WI 1990.

32. Sheldrick, G. M. SHELXL-93, Program for the Refinement of Crystal Structures, University of Göttingen, Germany 1993.

33. Krauss, W. and Gestrich, W. Chem. Technol. 6 (1977) 513.

34. Genie ${ }^{\circledR}$ Data Acquisition and Control Software, Version 1.1C, American Advantech Corporation, Sunnyvale, CA 1993.

Received February 12, 1999. 